\title{
A cognitive Approach for Evaluating the Usability of Storage as a Service in Cloud Computing Environment
}

\author{
Sharmistha Roy*, Prasant Kumar Pattnaik*, Rajib Mall** \\ * School of Computer Engineering, KIIT University, India \\ ** Department of Computer Science and Engineering, IIT Kharagpur, India
}

\begin{abstract}
Article Info
Article history:

Received Jul 15, 2015

Revised Dec 13, 2015

Accepted Jan 4, 2016

Keyword:

AHP model

Fuzzy

StaaS

Usability

ABSTRACT

Cloud computing is a style of computing which thrives users requirements by delivering scalable, on-demand and pay-per-use IT services. It offers different service models, out of which Storage as a Service (StaaS) is the fundamental block of Infrastructure cloud that fulfills user's excess demand of elastic computing resources. But considering the competitive business scenario choosing the best cloud storage provider is a difficult task. Thus, usability is considered to be the key performance indicator which evaluates the better cloud storage based on user's satisfaction. This paper aims to focus on the usability evaluation of StaaS providers namely Google drive, Drop box and One drive. This paper proposed a fuzzy based AHP model for measuring user satisfaction. Usability evaluation is carried out based on user feedback through Interview and Questionnaire method. Analysis of user feedback is done based on the fuzzy approach in order to remove vaguness. Whereas, AHP model is used for measuring satisfaction degree of the different cloud storage services and it solves the problem of selecting best cloud storage.
\end{abstract}

Copyright (C) 2016 Institute of Advanced Engineering and Science. All rights reserved.

\section{Corresponding Author:}

Prasant Kumar Pattnaik, School of Computer Engineering, KIIT University, Patia, Bhubaneswar, 751024, India.

Email: patnaikprasantfcs@kiit.ac.in, patnaikprasant@gmail.com

\section{INTRODUCTION}

Considering the recent economic scenario, users and enterprises are mainly driven towards highly available, reliable and cost-effective infrastructure and all those necessities are forcing towards the implementation of cloud computing environment. In the field of cloud computing, StaaS is a data storage model which facilitates cloud application to scale beyond their limited infrastructure. Although, cloud storage is having no definite architecture or set of capabilities, but it allows the enormous storage of user's data and the information without any underlying hardware cost. So, storage has become an essential and integral part of every human being. Importance of storage has reached such an extent that the idea of storing data in desktop/ PC's has become obsolete. To remove such constraint cloud storage came into the picture which facilitates mobility in retrieving, sharing and immediate access to data. Huge demand for getting access to data where and when people want, force the introduction of cloud storage providers.

In the last few years, numerous cloud storage providers came into existence but all that it requires is the best storage provider in terms of storage capacity, design feature, supported environment, economic scenario and security etc. Thus, usability evaluation is a satisfactory measure for finding out the best cloud storage for the fulfillment of user's requirement. Usability is a quality attributes which measures ease of use of any service or product, fulfill user's demands and meet user's satisfaction. Today's world support variety of free cloud storage providers for automatic upload of files to cloud storage, sharing of files across the 
world, to sync data across various devices which facilitates collaborative and productive work on the web. The past generation restricts enormous data storage and also don't provide the data availability facility across multiple devices which lead to immobility. This paper considers three most popularly used cloud storage providers namely Drop box, Google drive and One drive which all drives towards providing storage facility. But to rate the highly used StaaS provider, usability evaluation is conducted based on user feedback and for analyzing and measuring user satisfaction AHP and fuzzy approach is undertaken.

The rest of the paper is organized as follows: Section 2 describes the objective of the problem. In Section 3 the related works in usability evaluation and ranking of cloud service providers are mentioned. Section 4 and 5 describes the AHP model and Fuzzy approach respectively. The methodology of evaluating the usability of Cloud Storage as a Service is described in Section 6. Section 7 concludes the work.

\section{MOTIVATION \& OBJECTIVE}

Cloud StaaS is considered to be the future of the present day traditional storage devices (e.g. Pen drive, Hard-disk, CD, DVD etc.) where users will be able to host and store their data as well as application without regard to where the data is stored and what underlying hardware is required. Data stored in cloud environment should be available and can be accessed anytime from anywhere. Storage service providers should also guarantee that data stored should preserve the integrity and consistency for improving customer trust and relationship. Therefore, usability evaluation is essential to be carried out for providing customers with the best cloud StaaS. A pilot study has been conducted to identify the various features of cloud storage services. Storage capacity is one of the key requirements for Storage service providers followed with file sharing, online backup and archiving, easy navigation while accessing and uploading files. Applications designed should be flexible and scalable in order to improve market value and productivity.

\section{LITERATURE REVIEW}

Garg et al. [1] in their work proposed a novel framework which measures the Quality of Service (QoS) of cloud service providers and also compute Service Measurement Indexes (SMI) which is important for comparing and ranking different cloud services. QoS are measures based on several attributes proposed by Cloud Service Measurement Index Consortium CSMIC [2], which are further analyzed using AHP model that helps in ranking of the cloud services. The authors also designed the metrics for each QoS attributes which help in measuring the service level of each Cloud Service Provider (CSP). The proposed mechanism not only solves the problem of selecting the best CSP but also helps the service provider to improve the QoS.

Storage as a Service in cloud computing environment provides the mechanism for replication of local data and to keep synchronization across different platforms for maintaining consistency of data. For maintaining synchronization, data in local file systems need to be tracked regularly and for this purpose effective and rigid file organizations are required. Thus, Artiaga et al. in 2013 [3] have proposed a mechanism for improving the file system hierarchy by providing simultaneous views of the file system organization, known as name space virtualization. The methodology suggests the requirements and architecture for virtualization. Name space virtualization helps in improving the flexibility and usability of cloud-based services.

Zheng et. al [4] in their work presented a personalized cloud ranking framework to predict the ranking of different cloud services based on QoS without the invocations of additional services. The ranking is done with the help of two ranking algorithms namely Cloud Rank1 and Cloud Rank2. Experimental result shows that the proposed algorithm performs better than other rating algorithms.

Sundareswaran in 2012 [5], proposed an architecture which is based on cloud broker for selection of best cloud services. The proposed architecture provides two mechanisms- one for indexing the cloud service providers and another is the query algorithm for service selection. The authors have introduced the broker based approach in order to reduce the huge computational load done by users of similar preference for the selection of different cloud services from a huge pool of resources.

Patiniotakis et. al in 2013 [6], have addressed a framework for evaluating cloud services based on heterogeneous model of service characteristics and also proposed the metrics for ranking cloud services on the basis of varying level of fuzziness. The model allows for a unified method of multi-objective assessment of cloud services using AHP method. Moreover, the imprecise service characteristics and vague user preferences are analyzed using fuzzy approach.

A selection of best cloud service for specific application purpose is a difficult task. Thus, Jahani in 2014 [7] have proposed a W_SR (Weight Service Rank) methodology for cloud service ranking based on QoS features of different cloud services. Comparison with the other approaches shows that the proposed model is more flexible and scalable and can be used as the best service ranking algorithm. 
Rehman et al. [8] in 2014 proposed a method for selection of cloud services by utilizing the history of QoS of different service at different period of time and in parallel the analysis of the result is done using MCDM algorithm. TOPSIS and ELECTRE techniques are used as the MCDM algorithm. For better analysis, the user preferences are also considered from time to time which helps in the ranking of cloud services among the available service providers. The ranking also varies at different time period. Thus, results obtained at different time periods are combined to provide the overall rating of cloud services.

Kumar and Morarjee in [9] have designed a personalized structural framework for ranking of cloud services based on QoS. The proposed approach targets cloud application which require personal ranking with the support of optimal services. The framework named Cloud Rank also doesn't require any invocation of real world services.

Roy and Pattnaik [10] in 2013 have proposed usability evaluation techniques to evaluate the usability of web services based on specific usability attributes. The authors identified two new usability factors namely device independence and provision for physically disabled person in addition to the current attributes which enriches the quality of the web services and increase the global value of the products.

\section{AHP MODEL AND ITS CONSISTENCY CHECKING}

Analytic Hierarchy Process (AHP) model was developed by Prof. Thomas L. Saaty [11] which is a Multi-Criteria Decision Making (MCDM) model for complex problems. It analyses the the problem by decomposing into a hierarchy of goal, criteria, sub-criteria and alternatives. It derives the ratio scale weights from paired comparison instead of assigning them arbitrarily. Consider the following example which shows the pair-wise comparison matrix for three different criteria:

$$
A=\left(\begin{array}{lll}
1 & 3 & 5 \\
1 / 3 & 1 & 3 \\
1 / 5 & 1 / 3 & 1
\end{array}\right)
$$

Firstly the eighen vector of the matrix will be calculated which will be the weight matrix.

Steps for finding out weight of matrix A are described below:

- Sum of each column of the matrix A

- Divide each value across the column by its corresponding sum which will generate a new matrix B

- Sum of each row which gives (3 X 1) matrix

- $\quad$ Divide the matrix by the order of the matrix to get the weight matrix (w)

The resulting weight matix is:

$$
\mathrm{W}_{\mathrm{A}}=\left(\begin{array}{l}
0.63 \\
0.26 \\
0.31
\end{array}\right)
$$

Consistency of the matrix can be checked using the following steps:

- To compute $\lambda_{\max }$ for a pairwise comparison matrix the steps are mentioned below:

- Multiply each value of the first column of the matrix (A) by the weight of the first item. Similarly multiply each value of the second column by weight of the secong item and go on for the rest of matrix.

- Then sum the value across the rows of the resulting matrix to obtain the 'weight sum' matrix (B).

- $\quad$ Divide each value of $\mathrm{B}$ by the corresponding value of the weight matrix $\left(\mathrm{W}_{\mathrm{A}}\right)$.

- Compute the average of the values which becomes $\lambda_{\max }$

- Then the Consistency Index (CI) needs to be calculated using $\mathrm{CI}=\left(\lambda_{\max }-\mathrm{m}\right) /(\mathrm{m}-1)$, where $\mathrm{m}$ is the number of criteria.

Here CI of the matix $\mathrm{A}=(3.93-3) / 2=0.465$, where $\lambda_{\max }=3.93$ and no. of alternatives $=3$.

- Next Consistency Ratio is measured, which is the ratio of the consistency index to the corresponding random index i.e $\mathrm{CR}=\mathrm{CI} / \mathrm{RI}$.

Therefore, CR of the matrix $\mathrm{A}=0.465 / 0.58=0.8$

- If the value of CR is less than 0.1 then the matrix is consistent and it is acceptable otherwise the judgement has to be changed.

Since, the value of CR is more than 0.1 , hence the matrix is in-consistent. So, the pair-wise matrix needs to be changed. 


\section{FUZZY APPROACH}

Customer satisfaction is the only key for measuring the usability of any service or product. Interview and Questionnaire approach is one of the suitable usability evaluation methods to get feedback and rating of any product based on different sub-criteria. In our approach, rating of each question is done based on five different linguistic variables. But, in order to get the appropriate score of satisfaction for each subcriteria fuzzy approach [12] is adopted to convert the linguistic result into membership value. Hence, the fuzzy set theory is applied to handle the vagueness in human judgment. In our approach, each linguistic variable in converted to TFN [13] to achieve the appropriate score.

\section{METHODOLOGY OF USABILITY EVALUATION}

The proposed F-AHP approach can be sub-divided into following steps:

- Identification of criteria and sub-criteria

- Calculation of membership value of each sub-criteria corresponding to different alternatives based on customer feedback using TFN

- $\quad$ Pair-wise comparison of sub-criteria and its consistency checking

- Calculation of weight matrix for each criteria using AHP model

- Calculation of satisfaction degree of every criterion for different alternatives

\subsection{Identification of Criteria and Sub-Criteria}

As storage has become the integral value of modern lives and people demands a large amount of storage space available anywhere anytime, so cloud StaaS is an essential requirement for the sustenance of IT industry. In order to find out appropriate methodology to select best cloud StaaS, a pilot study has been conducted by experts from IT industry to identify the criteria and sub-criteria suitable for preparing Questionnaires based on which user feedback can be collected. User satisfaction degree on each of the criteria and sub-criteria will also help the service provider for improving its market value. Considering all those issues the following criteria and sub-criteria are taken which are mentioned below:

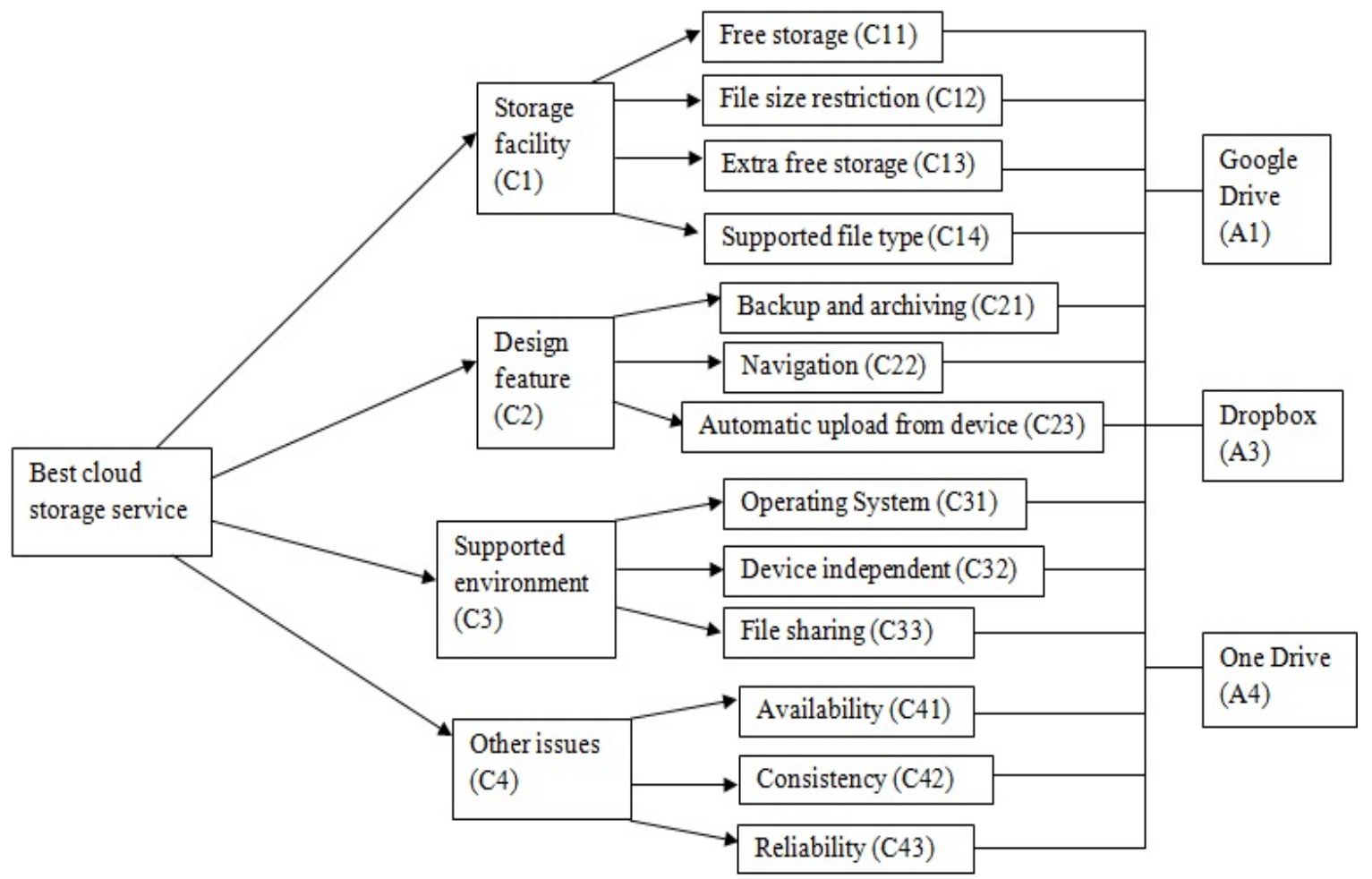

Figure 1. Hierarchical structure of selecting StaaS (Storage as a Service) provider 


\subsection{Calculation of Membership Value of Each Sub-Criterion Based on Customer Feedback using TFN}

The following procedures are undertaken to calculate the fuzzy membership value of the sub-criteria based on customer feedback.

6.2.1 Methodology of Usability evaluation:

Usability evaluation is conducted based on the Questionnaire-based evaluation, which involved responding to a standard questionnaire prepared through a pilot study based on the above criteria and subcriteria. Each questionnaire is associated with 5 different ratings based on some linguistic variables. Linguistic variables are mainly human judgments having no score but some words in natural language. A rating scale can be prepared against each linguistic variable for getting the score against each criterion as mentioned in Table 1 below.

Table 1. Rating scale of Linguistic variables

\begin{tabular}{lll}
\hline Linguistic variables & Symbol & Value \\
\hline Very Unsatisfactory & VUS & 2 \\
Unsatisfactory & US & 4 \\
Average & A & 6 \\
Satisfactory & S & 8 \\
Very Satisfactory & VS & 10 \\
\hline
\end{tabular}

Questionnaires are prepared based on expert group of people who are familiar with cloud storage service providers and cloud computing environment. The average of the score corresponding to each subcriterion is obtained and depicted below in Table 2.

Table 2. Average score of sub-criteria based on Linguistic scale

\begin{tabular}{|c|c|c|c|c|c|c|c|c|c|c|c|c|c|}
\hline \multirow[t]{2}{*}{$\begin{array}{l}\text { Cloud Storage } \\
\text { Providers }\end{array}$} & \multicolumn{4}{|c|}{ Storage Facility (C1) } & \multicolumn{3}{|c|}{ Design Feature (C2) } & \multicolumn{3}{|c|}{$\begin{array}{l}\text { Supported } \\
\text { Environment (C3) }\end{array}$} & \multicolumn{3}{|c|}{ Other issues $(\mathrm{C} 4)$} \\
\hline & $\mathrm{C} 11$ & $\mathrm{C} 12$ & $\mathrm{C} 13$ & $\mathrm{C} 14$ & $\mathrm{C} 21$ & $\mathrm{C} 22$ & $\mathrm{C} 23$ & C31 & C32 & $\mathrm{C} 33$ & $\mathrm{C} 41$ & $\mathrm{C} 42$ & $\mathrm{C} 43$ \\
\hline Drop Box & 6.3 & 8.2 & 8.0 & 9.0 & 8.6 & 8.8 & 8.3 & 9.7 & 9.8 & 8.4 & 9.16 & 9.48 & 8.3 \\
\hline Google Drive & 8.2 & 7.4 & 5.6 & 7.0 & 7.8 & 8.0 & 7.8 & 9.0 & 7.5 & 8.2 & 8.0 & 8.4 & 7.6 \\
\hline One-drive & 9.0 & 6.0 & 7.0 & 6.1 & 7.8 & 6.3 & 5.6 & 8.6 & 6.0 & 6.3 & 6.1 & 8.0 & 6.7 \\
\hline
\end{tabular}

\subsubsection{Conversion of Linguistic Variables to TFN}

Fuzzy is one of the powerful and best methods to represent linguistic variables. It removes vagueness of the human judgment by converting each linguistic variable into Triangular Fuzzy Number (TFN) [14] using Fuzzy Set Theory. TFN is a membership function which is associated with three variables $(a, b, c)$ where $a \& c$ are the end values and $b$ represent the peak value. The membership value of TFN lies between 0 and 1 . The fuzzy TFN is represented below:

$$
\mu_{\mathrm{LV}}(\mathrm{x})= \begin{cases}(\mathrm{x}-\mathrm{a}) /(\mathrm{b}-\mathrm{a}), & \mathrm{a} \leq \mathrm{x} \leq \mathrm{b}, \mathrm{a} \neq \mathrm{b} \\ (\mathrm{c}-\mathrm{x}) /(\mathrm{c}-\mathrm{b}), & \mathrm{b} \leq \mathrm{x} \leq \mathrm{c}, \mathrm{b} \neq \mathrm{c} \\ 0, & \text { otherwise }\end{cases}
$$

Here, $\mu_{\mathrm{LV}}(\mathrm{x})$ gives the membership value for the fuzzy scale $(\mathrm{a}, \mathrm{b}, \mathrm{c})$. Based on equation 1, each linguistic variable is converted to TFN with the corresponding scale given below in Table 3. 
Table 3. Linguistic variables and corresponding TFN

\begin{tabular}{lll}
\hline Linguistic variable & TFN & Membership Function \\
\hline Very Unsatisfactory (VUS) & $(0,0,3)$ & $\mu_{\text {VUS }}(\mathrm{x})= \begin{cases}0, & \mathrm{x}<0 \\
1 / 3(3-\mathrm{x}), & 0 \leq \mathrm{x} \leq 3\end{cases}$ \\
Unsatisfactory (US) & $(0,3,5)$ & $\mu_{\mathrm{US}}(\mathrm{x})= \begin{cases}1 / 3(\mathrm{x}-0), & 0 \leq \mathrm{x} \leq 3 \\
1 / 2(5-\mathrm{x}), & 3 \leq \mathrm{x} \leq 5\end{cases}$ \\
Average (A) & $(2,5,8)$ & $\mu_{\mathrm{A}}(\mathrm{x})= \begin{cases}1 / 3(\mathrm{x}-2), & 2 \leq \mathrm{x} \leq 5 \\
1 / 3(8-\mathrm{x}), & 5 \leq \mathrm{x} \leq 8\end{cases}$ \\
Satisfactory (S) & $(5,7,10)$ & $\mu_{\mathrm{S}}(\mathrm{x})= \begin{cases}1 / 2(\mathrm{x}-5), & 5 \leq \mathrm{x} \leq 7 \\
1 / 3(10-\mathrm{x}), & 7 \leq \mathrm{x} \leq 10\end{cases}$ \\
Very Satisfactory (VS) & $(7,10,0)$ & $\mu_{\mathrm{VS}}(\mathrm{x})= \begin{cases}1 / 3(\mathrm{x}-7), & 7 \leq \mathrm{x} \leq 10 \\
0, & \mathrm{x}>10\end{cases}$ \\
\hline
\end{tabular}

From the table, it can be noticed that the same range lies in more than one linguistic scale. To overcome this issue, that value is taken which fits the best (For e.g. if the score(x) is 8.1 then it lies in both Satisfactory and Very Satisfactory. Finding out the membership value for $\mathrm{x}$ it can be observed that for Satisfactory (S) its value is 0.6 and for Very Satisfactory (VS) its value is 0.4 . So the result will be considered as Satisfactory (since, $0.6>0.4)$ ).

Going on finding the membership value of each sub-criterion the customer satisfaction level can be obtained corresponding to each criterion for each of the alternatives in the form of matrix as shown below:

The average score obtained for every sub-criterion in Table 2 is converted to TFN using Membership function as mentioned in Table 3. So, the corresponding TFN of each sub-criterion (represented as $\mathrm{C}$ ) is given below in Table 4:

Table 4. TFN obtained for each criterion based on average score

\begin{tabular}{|c|c|c|c|c|c|c|c|c|c|c|c|c|c|}
\hline \multirow[t]{2}{*}{$\begin{array}{l}\text { Cloud Storage } \\
\text { Providers }\end{array}$} & \multicolumn{4}{|c|}{ Storage Facility (C1) } & \multicolumn{3}{|c|}{ Design Feature (C2) } & \multicolumn{3}{|c|}{$\begin{array}{l}\text { Supported } \\
\text { Environment (C3) }\end{array}$} & \multicolumn{3}{|c|}{ Other issues (C4) } \\
\hline & $\mathrm{C} 11$ & $\underline{\mathrm{C} 12}$ & $\underline{\mathrm{C} 13}$ & $\mathrm{C} 14$ & $\underline{\mathrm{C} 21}$ & $\mathrm{C} 22$ & $\mathrm{C} 23$ & $\mathrm{C} 31$ & $\mathrm{C} 32$ & $\mathrm{C} 33$ & $\mathrm{C} 41$ & $\mathrm{C} 42$ & $\mathrm{C} 43$ \\
\hline Drop Box & $\begin{array}{l}(5, \\
7, \\
10)\end{array}$ & $\begin{array}{l}(5, \\
7, \\
10)\end{array}$ & $\begin{array}{l}5, \\
7, \\
10)\end{array}$ & $\begin{array}{l}(7, \\
10, \\
10)\end{array}$ & $\begin{array}{l}(7, \\
10, \\
10)\end{array}$ & $\begin{array}{l}(7, \\
10, \\
10)\end{array}$ & $\begin{array}{l}(5, \\
7, \\
10)\end{array}$ & $\begin{array}{l}(7, \\
10, \\
10)\end{array}$ & $\begin{array}{l}(7, \\
10, \\
10)\end{array}$ & $\begin{array}{l}(5, \\
7, \\
10)\end{array}$ & $\begin{array}{l}(7, \\
10, \\
10)\end{array}$ & $\begin{array}{l}(7, \\
10, \\
10)\end{array}$ & $\begin{array}{l}(5, \\
7, \\
10)\end{array}$ \\
\hline Google Drive & $\begin{array}{l}(5, \\
7, \\
10)\end{array}$ & $\begin{array}{l}(5, \\
7, \\
10)\end{array}$ & $\begin{array}{l}(2, \\
5,8)\end{array}$ & $\begin{array}{l}(5, \\
7, \\
10)\end{array}$ & $\begin{array}{l}(5, \\
7, \\
10)\end{array}$ & $\begin{array}{l}(5, \\
7, \\
10)\end{array}$ & $\begin{array}{l}(5, \\
7, \\
10)\end{array}$ & $\begin{array}{l}(7, \\
10, \\
10)\end{array}$ & $\begin{array}{l}(5, \\
7, \\
10)\end{array}$ & $\begin{array}{l}(5, \\
7, \\
10)\end{array}$ & $\begin{array}{l}(5, \\
7, \\
10)\end{array}$ & $\begin{array}{l}(5, \\
7, \\
10)\end{array}$ & $\begin{array}{l}(5, \\
7, \\
10)\end{array}$ \\
\hline One-drive & $\begin{array}{l}(7, \\
10, \\
10)\end{array}$ & $\begin{array}{l}(2, \\
5, \\
8)\end{array}$ & $\begin{array}{l}(5, \\
7, \\
10)\end{array}$ & $\begin{array}{l}(2, \\
5, \\
8)\end{array}$ & $\begin{array}{l}(5, \\
7, \\
10)\end{array}$ & $\begin{array}{l}(5, \\
7, \\
10)\end{array}$ & $\begin{array}{l}(2, \\
5, \\
8)\end{array}$ & $\begin{array}{l}(7, \\
10, \\
10)\end{array}$ & $\begin{array}{l}(2, \\
5, \\
8)\end{array}$ & $\begin{array}{l}(5, \\
7, \\
10)\end{array}$ & $\begin{array}{l}(2, \\
5, \\
8)\end{array}$ & $\begin{array}{l}(5, \\
7, \\
10)\end{array}$ & $\begin{array}{l}(5, \\
7, \\
10)\end{array}$ \\
\hline
\end{tabular}

\subsection{Pair-Wise Comparison of Sub-Criteria and its Consistency Checking}

Pair-wise comparison matrix is essential in order to establish the importance of each sub-criterion with respect to the other. From the hierarchical structure of the proposed model, the priorities of the subcriteria need to be established. Pair-wise comparisons are done based on the AHP technology. When comparing a pair of sub-criteria a ratio of importance is established based on the below standard scale given below by Saaty: 
Table 5. Scale of relative importance of one criteria w.r.t to other criteria

\begin{tabular}{|c|c|c|}
\hline $\begin{array}{l}\text { Value of } \\
\text { importance }\end{array}$ & Definition & Explanation \\
\hline 1 & Equally important & Two criteria are of the same importance \\
\hline 3 & Slightly important & $\begin{array}{l}\text { One criteria is slightly important than the other based on the } \\
\text { judgement }\end{array}$ \\
\hline 5 & Strongly important & $\begin{array}{l}\text { One criteria is strongly important than the other based on the } \\
\text { judgement }\end{array}$ \\
\hline 7 & Very strongly important & $\begin{array}{l}\text { One criteria is very strongly important than the other criteria } \\
\text { based on experiment and judgement }\end{array}$ \\
\hline 9 & Extremely important & One criteria varies extremely with respect to the other criteria \\
\hline $\begin{array}{l}2,4,6,8 \\
\text { Reciprocal of } \\
\text { above non-zero } \\
\text { values }\end{array}$ & $\begin{array}{l}\text { Intermediate value between the judgement } \\
\text { If criteria } c_{i} \text { has one of the above non-zero } \\
\text { value when compared with } c j \text {, then } c_{j} \text { will } \\
\text { take the reciprocal of that value. }\end{array}$ & Values are taken when compromise is requiered \\
\hline
\end{tabular}

Pair-wise comparison of the sub-criteria is established based on the pilot study done with the experts of the in order to establish correct and consistent value.

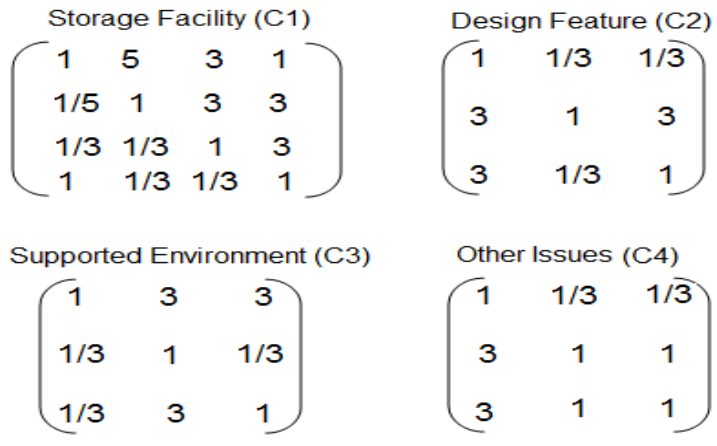

Figure 2. Pair-wise comparison matrix for each criterion

Following the above method for consistency checking of pair-wise comparison matrix, as discussed in section 4, the Consistency Ratio (CR) is analyzed using AHP model. Following are the consistency ratio $(\mathrm{CR})$ of the above mentioned pair-wise comparison for each criterion:

Table 6. Consistency Ratio of different criterion in AHP model

\begin{tabular}{ll}
\hline Criteria & Consistency Ratio \\
\hline Storage Facility (C1) & 0.41 \\
Design Feature (C2) & 0.10 \\
Supported Environment (C3) & 0.10 \\
Other Issues (C4) & 0 \\
\hline
\end{tabular}

\subsection{Calculation of Weight Matrix for Each Criteria using AHP Model}

According to the AHP model the weight matrix for every criterion is calculated below:

$$
\mathrm{W}_{\mathrm{C} 1}=\left(\begin{array}{l}
0.42 \\
0.26 \\
0.18 \\
0.16
\end{array}\right) \quad \mathrm{W}_{\mathrm{C} 2}=\left(\begin{array}{l}
0.14 \\
0.57 \\
0.29
\end{array}\right) \quad \mathrm{W}_{\mathrm{C} 3}=\left(\begin{array}{l}
0.57 \\
0.14 \\
0.29
\end{array}\right) \quad \mathrm{W}_{\mathrm{C} 4}=\quad\left(\begin{array}{l}
0.14 \\
0.43 \\
0.43
\end{array}\right)
$$

In order to fit the value in standard (1-10) scale as defined for Linguistic variable each value is multiplied by 10 . Therefore, the weight age of Free storage $(\mathrm{C} 11)=4.2$, File size restriction $(\mathrm{C} 12)=2.6$, Extra free storage $(\mathrm{C} 13)=1.8$, Supported file type $(\mathrm{C} 14)=1.6$.

Whereas, the weight age of Backup and Archiving $(\mathrm{C} 21)=1.4$, Navigation $(\mathrm{C} 22)=5.7$ and Automatic upload from device $=2.9$. 
The weight age of the corresponding sub-criteria's of Supported environment (C3) are Operating system $(\mathrm{C} 31)=5.7$, Device independent $(\mathrm{C} 32)=1.4$, File sharing $(\mathrm{C} 33)=2.9$.

Finally, Other Issues (C4) have its respective weight age of the sub-criteria as Availability $(\mathrm{C} 41)=$ 1.4, and both Consistency (C42) and Reliability (C43) $=4.3$.

The weight matrix of each criterion is also converted to TFN using Membership Function as mentioned in Table 3 as shown below in Table 7:

Table 7. TFN obtained for weight matrix of different sub-criterion

\begin{tabular}{lllllllllllllll}
\hline $\begin{array}{l}\text { TFN scale for the } \\
\text { weight matrix of each } \\
\text { criterion }\end{array}$ & \multicolumn{10}{ll}{ Storage Facility (C1) } & \multicolumn{1}{c}{ Design Feature (C2) } & \multicolumn{2}{l}{$\begin{array}{l}\text { Supported } \\
\text { Environment (C3) }\end{array}$} & Other issues (C4) \\
& $\mathrm{W}_{\mathrm{C} 11}$ & $\mathrm{~W}_{\mathrm{C} 12}$ & $\mathrm{~W}_{\mathrm{C} 13}$ & $\mathrm{~W}_{\mathrm{C} 14}$ & $\mathrm{~W}_{\mathrm{C} 21}$ & $\mathrm{~W}_{\mathrm{C} 22}$ & $\mathrm{~W}_{\mathrm{C} 23}$ & $\mathrm{~W}_{\mathrm{C} 31}$ & $\mathrm{~W}_{\mathrm{C} 32}$ & $\mathrm{~W}_{\mathrm{C} 33}$ & $\mathrm{~W}_{\mathrm{C} 41}$ & $\mathrm{~W}_{\mathrm{C} 42}$ & $\mathrm{~W}_{\mathrm{C} 43}$ \\
\hline TFN scale & $(2$, & $(0$, & $(0$, & $(0$, & $(0$, & $(2$, & $(0$, & $(2$, & $(0$, & $(0$, & $(0$, & $(2$, & $(2$, \\
& 5, & 3, & 3, & 3, & 0, & 5, & 3, & 5, & 0, & 3, & 0, & 5, & 5, \\
& $8)$ & $5)$ & $5)$ & $5)$ & $3)$ & $8)$ & $5)$ & $8)$ & $3)$ & $5)$ & $3)$ & $8)$ & $8)$ \\
\hline
\end{tabular}

\subsection{Calculation of Satisfaction Degree of Every Criterion for Different Alternatives}

Satisfaction degree for every criterion is very essential in order to find out the lackingness of the service. It also measures the best cloud storage provider. The satisfaction degree of each criterion can be calculated as:

Satisfaction degree $\left(\mathrm{Z}_{\mathrm{Ci}}\right),(\mathrm{i}=1,2, . ., \mathrm{n})=\left(\frac{1}{\sum_{\mathrm{i}=1}^{\mathrm{n}} \mathrm{w}_{\mathrm{C} 1 \mathrm{i}}} \sum_{\mathrm{i}=1\left(\mathrm{C} 1 \mathrm{i} \times \mathrm{W}_{\mathrm{C} 1 \mathrm{i}}\right)}^{\mathrm{n}}\right.$

Each sub-criterion comes with different weight. So, weight of each sub-criterion is defined by the peak value i.e $\mathrm{C}_{\mathrm{P}}$ for $\mathrm{TFN}\left(\mathrm{C}_{1}, \mathrm{C}_{\mathrm{P}}, \mathrm{C}_{2}\right)$

Therefore weight of $\mathrm{Ci}(\mathrm{i}=1,2, \ldots \mathrm{n})=\sum_{\mathrm{i}=1}^{4} \mathrm{~W}_{\mathrm{C} 1 \mathrm{i}}=\sum_{\mathrm{i}=1}^{4} \mathrm{C}_{\mathrm{pi}}$

For Dropbox, the satisfaction degree of each criteria is calculated below:

Weight of $\mathrm{C} 1$ for Dropbox is calculated using equation 3 below:

$$
\sum_{\mathrm{i}=1}^{4} \mathrm{~W}_{\mathrm{C} 1 \mathrm{i}}=14
$$

Using equation 2 , the satisfaction degree of Storage facility $\left(\mathrm{Z}_{\mathrm{C} 1}\right)=\frac{10}{14}, \frac{107}{14}, \frac{230}{14}$ given below:

The integral values of the linguistic variables can be obtained using the optimization technique as

$$
\left(\mathrm{t}_{\mathrm{o}}+\mathrm{t}_{\mathrm{p}}+4 \mathrm{t}_{\mathrm{m}}\right) / 4
$$

where, $t_{\mathrm{o}}=$ optimistic value, $\mathrm{t}_{\mathrm{p}}=$ pessimistic value and $\mathrm{t}_{\mathrm{m}}=$ most likely value.

So, the integral values of the TFN of the linguistic variables are calculated using equation 4 and shown in table 8 below:

Table 8. Integral value of different linguistic variables

\begin{tabular}{lllllll}
\hline $\begin{array}{l}\text { Linguistic } \\
\text { term }\end{array}$ & $\begin{array}{l}\text { Very Unsatisfactory } \\
\text { (VUS) }\end{array}$ & $\begin{array}{l}\text { Unsatisfactory } \\
\text { (US) }\end{array}$ & Average (A) & Satisfactory (S) & $\begin{array}{l}\text { Very } \\
\text { (VS) }\end{array}$ & Satisfactory \\
\hline Integral Value & 0.5 & 2.83 & 5 & 7.17 & 9.5 & \\
\hline
\end{tabular}

Hence, integral value of $\mathrm{Z}_{\mathrm{C} 1}$ (calculated using equation 4) for Drop Box $=8.0$, which lies between 'Satisfactory' and 'Very Satisfactory'. Table 9 shows the integral value of each criterion for every alternative. 
Table 9. Integral value of different criterion for each alternative

\begin{tabular}{lllll}
\hline Cloud Storage Providers & Storage Facility (C1) & Design Feature (C2) & Supported Environment (C3) & Other issues (C4) \\
\hline Drop Box & 8.0 & 9.55 & 9.55 & 9.23 \\
Google Drive & 7.12 & 8.21 & 9.55 & 8.17 \\
One Drive & 7.47 & 7.5 & 9.42 & 8.07 \\
\hline
\end{tabular}

So, the overall satisfaction degree of Drop Box $=36.33$, Google Drive $=33.05$ and One Drive $=$ 32.46 as shown in figure 3 below.

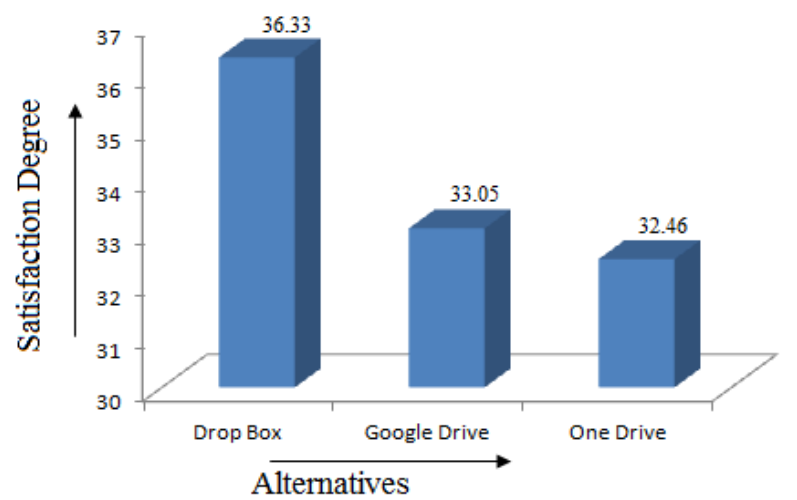

Figure 3. Overall Satisfaction degree of different alternatives

Hence, from the above table it signifies that Drop Box is having better customer satisfaction for each of the criteria with respect to other cloud storage providers. Hence, the rating of the above cloud storage provider is Drop Box $>$ Google Drive $>$ One Drive.

\section{PR ACTICAL IMPORTANCE OF THE WORK}

Storage-as-a-Service is gaining more importance in recent times because of its ability to provide enormous storage space on pay-as-you-go fashion. Thus, it optimizes the use of disk storage space and minimizes the back-end storage costs. Many research works [15, 16, 17] focuses on finding out the best aspect of the storage services in terms of finding out the SLA parameters to measure the quality of the StaaS providers. The research work [15] categorized the SLA parameters of storage services into two categories namely, trivial and non-trivial parameters based on Service Level Objectives (SLOs). The trivial SLA parameter includes availability and the non-trivial parameters are fault tolerance, performance, disaster recovery, Security, Governance, Data Life Cycle Management and error rate. Moreover, some work [16] focuses on some parameters for measuring the performance of the storage services namely Upload/Download speeds at Different Times, Upload/Download speed of Different files and CPU utilization which may vary based on network condition, file types and file size. The research work mentioned in [17] focuses on measuring the usability of software as a service i.e. websites by using questionnaire method and statistical approach. The performances of the websites are measured using number of clicks, task completion time and task success rate. Whereas, the questionnaire method used WAMMI questionnaire set to measure the subjective opinion of the users regarding the best aspect of the websites in terms of attractiveness, controllability, efficiency, learnability and helpfulness.

Whereas, in our proposed work we identified the several attributes and sub-attributes which provide better visibility in terms of determining the usability of Storage-as-a-Service in cloud computing environment. The attributes identified for measuring the usability of cloud storage service providers are Storage Facility, Design Feature, Supported Environment and Other miscellaneous issues which are further divided into sub-attributes namely file storage, file size restriction, extra free storage, supported file type, backup and archiving, navigation, automatic upload from device, operating system, device independent, file sharing, availability, consistency, reliability. The attributes are measured using user feedback mechanism which is analysed using a fuzzy approach which provides significant insight to the research work. 


\section{CONCLUSION}

In this paper, we have used the fuzzy approach to show the significance of linguistic variables which are used for user feedback. Moreover, the AHP model is employed for selection of cloud storage providers. The combination of both gives a promising outcome. This article paves a way to include four different criteria of cloud StaaS which are further divided into sub-criteria. Triangular Fuzzy Number is used for generating the weight matrix for different criterion and used for user feedback matrix. Satisfaction degree obtained for each criterion signifies the usability of the cloud storage and it also gives feedback to the service provider regarding the best aspect as well as the drawback of the cloud storage. Questionnaire method used for getting user feedback serves as the best usability evaluation technique. It enables the cloud service provider to improve the service quality and increase the market value. In future scope of work other usability crietria may be considered for the improvement of user satisfaction level of consumers as well as cloud storage providers.

\section{REFERENCES}

[1] S.K. Garg, et al., "SMICloud: A Framework for Comparing and Ranking Cloud Service", in Fourth IEEE International Conference on Utility and Cloud Computing, 2011, pp. 210-218.

[2] C.S.M.I.C. (CSMIC), "SMI Framework" URL http://betawww.cloudcommons.com/servicemeasurementindex.

[3] E. Artiaga, et al., "Better Cloud Storage Usability Through Name Space Virtualization", in 6 ${ }^{\text {th }}$ IEEE/ACM International Conference on Utility and Cloud Computing, 2013, pp. 67-74.

[4] Z. Zheng, et al., "QoS Ranking Prediction for Cloud Services", IEEE Transactions on Parallel and Distributed Systems, vol. 24(6), pp. 1213-1222, 2013.

[5] S. Sundareswaran and A. Squicciarini, D. Lin, "A Brokerage-Based Approach for Cloud Service Selection", in $5^{\text {th }}$ IEEE International Conference on Cloud Computing, 2012, pp. 558-565.

[6] I. Patiniotakis, et al., "Managing Imprecise Criteria in Cloud Service Ranking with a Fuzzy Multi-criteria Decision Making Method", Service-Oriented and Cloud Computing, LNCS, vol. 8135, pp. 34-48, 2013.

[7] X. Jahani, et al., "W_SR: A QoS Based Ranking Approach for Cloud Computing Service", Computer Engineering and Applications Journal, vol. 3(2), pp. 55-62, 2014.

[8] Z.U. Rehman, et al., "Parallel Cloud Service Selection and Ranking Based on QoS History", International Journal of Parallel Programming, vol. 42, pp. 820-852, 2014.

[9] G.P. Kumar and K. Morarjee, "Ranking prediction for cloud services from the past usages", International Journal of Computer Sciences and Engineering, vol. 2(9), pp. 22-25, 2014.

[10] S. Roy and P.K. Pattnaik, "Some Popular Usability Evaluation Techniques for Websites", Advances in Intelligent Systems and Computing, vol. 247, pp. 535-543, 2013.

[11] T.L. Saaty, "How to Make a Decision: The Analytic Hierarchy Process," Interfaces, vol. 24(6), pp. 19-43, 1994.

[12] L.A. Zadeh, "Fuzzy Sets", Information and Contro, vol. 8(5), pp. 338-353, 1965.

[13] T.S. Liou and C.W. Chen, "Subjective appraisal of service quality using fuzzy linguistic evaluation", International Journal of Quality and Reliability Management, vol. 23(8), pp. 928-943, 2006.

[14] J.J. Cronin and S.A. Taylor, "Measuring service quality: a re-examination and extension", Journal of Marketing, vol. 56(7), pp. 55-68, 1992.

[15] N. Ghosh and S.K. Ghosh, "An Approach to Identify and Monitor SLA Parameters for Storage-as-a-Service Cloud Delivery Model", in First International Workshop on Management and Security Technologies for Cloud Compuitng, 2012, pp. 724-729.

[16] X. Zhang, et al., "Performance Evaluation of Online Backup Cloud Storage", International Journal of Cloud Applications and Computing, vol. 3(3), pp. 20-33, 2013.

[17] S. Roy et al., "A quantitative approach to evaluate the usability of academic websites based on human perception", Egyptian Journal of Informatics, vol. 15(3), pp. 159-167, 2014.

\section{BIOGRAPHIES OF AUTHORS}

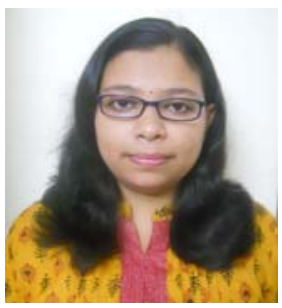

Sharmistha Roy received the B.Tech and M.Tech degrees in Computer Science and Engineering from National Institute of Technology Agartala, in 2010 and 2012, respectively and pursuing her $\mathrm{PhD}$ in the field of Cloud Computing and Usability Measurement from KIIT University. Moreover, she has received Gold medal during her M.Tech. Her research area includes: Cloud Usability, Security, and Software Engineering 


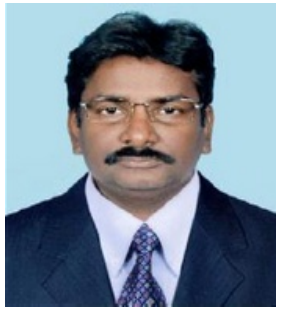

Dr. Prasant Kumar Pattnaik is currently working as a Professor, in School of Computer Engineering, KIIT University, Bhubaneswar. He is a Senior Member of IEEE, Fellow Member of IETE, Senior member of IACSIT. His research area includes: Cloud Computing, Usability Engineering, Green Computing, MANET, Wireless Sensor Network.

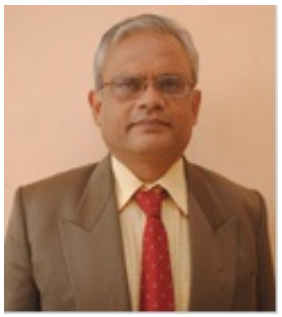

Dr. Rajib Mall is a Professor and Head in the Department of Computer Science and Engineering at IIT Kharagpur. He has vast practical experience in developing industry-oriented software products. Having an academic experience of a decade and half in IIT Kharagpur, Professor Rajib Mall has guided several doctoral dissertations and published over a hundred research articles. 